\title{
A Study into the Results of an Intervention Program of Linguistic Skills in English (L2) and Its Effect on Hebrew (L1) among Poor Readers: An Examination of the Cognitive-Retroactive Transfer (CRT) Hypothesis
}

\author{
Salim Abu-Rabia, Dana Bluestein-Danon \\ Faculty of Education, University of Haifa, Haifa, Israel \\ Email: salimar@construct.haifa.ac.il
}

Received July $30^{\text {th }}, 2012$; revised August $27^{\text {th }}, 2012$; accepted September $3^{\text {rd }}, 2012$

\begin{abstract}
The present study examined whether an improvement in English as a second language causes an improvement among poor readers in Hebrew as the first language. This assumption is named in the present study "The Cognitive-Retroactive Transfer (CRT) hypothesis of linguistic skills". The participants were 20 sixth-grade poor readers from Israeli elementary schools, with Hebrew as their first language, and who learn English as their second language. All the students in the program participated in small group instruction sessions that emphasized linguistic and meta-linguistic skills in the second language (English). The program, which was administered over a 5 -month period, involved approximately 40 hours of contact with a trained instructor. The participants were administered various tests which measured their basic linguistic skills in English as well as in Hebrew. The tests were as follows: phonological awareness, phonological processing, word identification, reading fluency, reading comprehension, morphological awareness, syntactic awareness, orthographic knowledge and spelling. The tests in both languages were given to the participants before and after the intervention program. The test results indicated significant differences both in English and in Hebrew before and after the intervention program for all linguistic skills (except orthographic knowledge). The findings provide scientific support for the Cognitive-Retroactive Transfer (CRT) hypothesis, which means that an improvement in linguistic and meta-linguistic skills in a second language will be expected to give rise to a similar improvement in the first language as well. The results are discussed in light of the findings in the literature as well as suggestions for future research.
\end{abstract}

Keywords: English as a Second Language; Hebrew as the First Language; Cognitive-Retroactive Transfer (CRT) Hypothesis; Meta-Cognitive Abilities; Modular Process

\section{Introduction}

It is generally accepted that poor readers suffer significant difficulties in learning a second language (Geva, YaghoubZadeh, \& Schuster, 2000). Specifically, poor readers with low linguistic skills on their first language will also present low linguistic skills on their second language. The reason for the difficulties being that the same meta-linguistic skills related to literacy, such as phonological awareness, orthographic knowledge, syntactic awareness, etc., are common to all languages, so that poor skills in one language will be manifested as poor skills in a second language (Geva, 1995). That is to say, difficulties of poor readers in a second language are as a result of poor skills in the first language (Leikin, Share, \& Schwartz, 2005). The consequence is that improved linguistic skills in a first language will also result in improved linguistic skills in a second language. The question is does this phenomenon can take place in the opposite way as well.

The purpose of the present study is to check whether improvement in literacy meta-linguistic skills in English as a second language will result in improved similar skills in Hebrew as a first language. This phenomenon will be labeled in this study as Cognitive Retroactive Transfer-CRT. It can be as- sumed that a poor reader who learns literacy in a particular language (even if it is a second language) will reach, by a special method fitted for his/her specific needs, higher meta-linguistic awareness in this language. Since studies made in this realm show that linguistic skills in the first language are transferred to a second language, it is assumed that these skills could also be transferred from a second to a first language. Thereby, a CRT phenomenon will be taking place. Since this subject has not yet been researched empirically, it is taken as a framework for this study.

\section{Reading Development in L2}

The research literature for the development of reading skills in a second language raises the following questions: Will linguistic skills that were found as effective for predicting acquisition of reading skills in a first language also predict acquisition of reading skills in a second language? Also, is it possible to identify difficulties for a subject learning a second language by his/her skills in the first language? There are various studies examining those questions. For example, there are findings indicating that phonological awareness in a first language (L1) predicts decoding skills and word identification not only in the 
L1 but also in a second language (L2) (Cisero \& Royer, 1995). Additional studies found that phonological decoding in the L1 is highly correlated with acquisition of reading skills in the L2; Phonological awareness was determined as a major component in predicting reading achievements in two languages, independent to the nature of the native tongue (Muter \& Diethelm, 2001; Quiroda, Lemos-Britton, Mostafapour, Abbott, \& Berninger, 2002).

In relation to this skill of phonological awareness, it was argued that since the segmentation of a word to its phonemes is not specific for a given language, then it stands to reason that when this ability is well developed for one language, it will be well developed for another language as well, and will serve as a base for decoding skills in general (Koda, 2007).

Sparks (1995) argued that not only does phonological awareness in the L1 contribute to learning the L2, but also other skills of the first language assist in learning the second language. He indicated that skills, such as phonology, orthography, syntax and semantics, in writing and speech in the first language-serve as a base for successful learning of a second language. He assumed as well that learning both first and second languages depend on basic mechanisms for language acquisition and that problems in certain skills, like phonological or orthographical processing, will have negative influence on both first and second language learning.

In other studies which investigated reading skills in a second language among poor readers, it was found that they present difficulties in phonological processing, syntax awareness and working memory as poor readers in the first language (AbuRabia \& Siegel, 2003). Also, in the studies of Leikin and colleagues (2005), it was found that failure in phonological awareness in the first language among children with Russian as the native tongue constituted the major difficulty in acquiring Hebrew reading skills as a second language. In another study by Gholamain \& Geva (1999), where a significant correlation was found between phonological awareness in the first language and second language, a weak phonological awareness among poor readers in both languages was also present.

There is an assumption relating to causes of difficulties in second language reading. According to this assumption, in order to read in a second language, a level of second language linguistic ability must first be achieved. This is the Linguistic Threshold Hypothesis (Cummins, 1991). Cummins defined the "Linguistic Threshold" as a certain level of morphological, syntactic and lexical knowledge in a foreign language. Readers with a low "Linguistic Threshold" will find it difficult to use reading comprehension strategies from L1 to L2. In contrast, readers with a high "Linguistic Threshold" will not have problems in transferring these skills (Lee \& Schallert, 1997).

Despite the prevalent belief that poor first language readers will have difficulties in reading a second language, surprisingly some other studies had opposite results. For instance, Sparks, Philips, \& Javorsky (2003) found that students with reading disabilities do not necessarily suffer learning difficulties in a second language. This is because most of the students in their study had their second language courses in an academic institute with their grades being average and above.

Also, in another research conducted in Sweden, a number of English teachers reported cases where students with learning disabilities read English as an L2 better than Swedish as an L1. These students preferred reading English texts and performed better in English classes than in Swedish (Miller-Guron \&
Lundberg, 2000). They reasoned that social, emotional and motivational factors could be behind the observation. It is a fact that many children are exposed to English through TV, computer and music - a factor that assists in the learning process. Furthermore, differences in the orthographies between the two languages could also take parts. In a study that tested the influence of orthography in a first language on reading speed and comprehension, it was found that English texts as L1 were read significantly faster than Hebrew texts as L1, and this despite the fact that the English texts contained $40 \%$ more words (Shimron \& Sivan, 1994). These authors claimed that differences in the orthographic character of a language play a role in this matter.

\section{Characterization of English and Hebrew Orthographies}

In order to show how the differences in orthographic character can affect reading development, the following review is presented.

Hebrew is written from right to left and all verbs and most nouns contain consonantal roots, which are combined with additional letters to form words. When Hebrew is written with vowel symbols (vowelized Hebrew), it is considered orthographically "shallow", reflecting a direct and consistent graphemephoneme correspondence (Eviatar \& Ibrahim, 2004). When Hebrew is written without the vowel symbols (unvowelized Hebrew), it is considered to be orthographically "deep", meaning that the grapheme-phoneme correspondence is unpredictable (Abu-Rabia \& Siegel, 2003). The vowelized Hebrew appears mainly in texts for beginning readers, whereas the unvowelized Hebrew is for skilled readers. This situation means that an unvowelized word could be pronounced in different ways. The skilled reader must rely on the context of the word in the sentence in order to pronounce it correctly.

The English language, on the other hand, is written from left to right and is considered to be orthographically "deep" (AbuRabia \& Siegel, 2003). Also, the vowels are represented by means of letters, which are part of the alphabet and appear within the words themselves, so that unlike Hebrew, words are written identically for beginners and skilled readers alike (AbuRabia \& Siegel, 2003). As a result, readers of English must rely more on the orthography of the word and less on the phonological processing.

It is argued that while developing reading skills among individuals with reading disabilities, because of their difficulty in phonological processing, it is possible that they learned to pay more attention to the visual orthography form of the word, rather than its pronunciation (Siegel, Share, \& Geva, 1995). The consequence of that for this kind of readers is that reading a "deep" orthographic language which requires the use of orthographic processing, will constitute for them an easier task compared to reading a "shallow" orthographic language, such as vowelized Hebrew, where phonological processing is necessary (Siegel et al., 1995). Koda (1999) found that the closer the orthographies of a first and a second language, the easier it is for students to reach quicker and more accurate word identification in a second language.

\section{Linguistic Interdependence Hypothesis- The Cross-Language Transfer of Linguistic Skills}

A hypothesis introduced by Cummins (1991), called the 
Linguistic Interdependence Hypothesis, assumes that if the external environment provides an adequate stimulus for preservation of a first language, then intensive exposure to a second language at school will contribute significantly to a bilingual development, without having any negative influences on the first language. It was also argued that in the extent of which an effective teaching program advances literacy in a certain language, transfer of that linguistic knowledge to an other language will occur, in the condition of adequate exposure to the other language and also adequate motivation to learn the language.

This hypothesis predicts that in a bilingual program, teaching reading skills in one language not only improves literacy in that language, but also leads to a deep conceptual linguistic knowledge, which significantly related to literacy and to general academic skills in an other language. In other words, although superficially certain aspects, such as orthography or fluency, seem to develop separately, a cognitive academic basis exists for all languages. These basic and common abilities facilitate the transfer of cognitive academic skills relating to literacy that are common to all languages (Cummins, 1991). Research data which support the above hypothesis will be presented in the next section.

\section{Inter-Linguistic Skills and the Difficulties in Processing Different Orthographies}

Evidence for the transfer of phonological skills between languages was found in many studies. For instance, in a study that investigated the inter-linguistic connection in phonological and orthographic components among bilingual children learning to read in two alphabetic languages - Korean and English, a very high correlation was found between phonological skills in the first and second languages (Wang, Park, \& Lee, 2006). In this study, a significant correlation was also found between phonological skills in Korean and reading of words and non-words in English. More evidence for the transfer of phonological skills between languages was found in another study (Verhoeven, 1994), where significant correlation between phonological skills in the L1 (Turkish) and L2 (Dutch) was found.

As for orthographic skills which are required for the reading process as well, it was found that among bilingual children learning to read English and Korean, no significant correlation was found between the orthographic skills in the two languages (Wang et al., 2006). It should be noted that whereas English is recognized as having a "deep" orthographic character, Korean is a "shallow" orthographic language. Also, in another study which investigated transfer of skills between English and Chinese (a non-alphabetic language), it was found that Chinese orthographic skills did not predict reading skills performance in English (Wang, Perfetti, \& Liu, 2005).

As for reading comprehension skills, evidence is presented showing that reading comprehension in a first language contributes to comprehension in a second language (Van Gelderen et al., 2004). A theory that explains the connection between various components in a second language and reading comprehension argues that reading comprehension in a second language involves mainly application of metacognitive skills (Goodman, 1971). Metacognitive reading skill is the ability to use strategies in order to regulate the reading process. For instance, reading a text for the purpose of locating a piece of information requires another type of strategy than reading a text for the purpose of memorizing. The method whereby a reader adjusts his strategies according to the specific purpose reflects his metacognitive skills.

Evidence for inter-linguistic reading fluency as defined in terms of speed and accuracy was found in a study where reading fluency development was examined among first and second grade children studying concurrently English as the L1 and Hebrew as the L2 (Geva, Wade-Wooley, \& Shany, 1997). In this study, it was found that despite different orthographies between English and the vowelized Hebrew (with vowel symbols), a significant correlation exists between the accuracy and speed of reading isolated words in one language and that of the other language. Also, in another research testing reading fluency in Spanish as the L1 and English as the L2 among primary school pupils (grades $1-6$ ), the results show a positive significant correlation between fluencies in English and Spanish (Domínguez De Ramírez \& Shapiro, 2007).

As for spelling skills, a study looking for components in a first language, which will predict reading and spelling performance in a second language, discovered that the linguistic components which were very useful in predicting spelling performance in a second language were the spelling and phonological awareness in a first language (Sparks, Patton, Ganschow, Humbach, \& Javorsky, 2008). Furthermore, in a study by Abu Rabia \& Siegel (2002), it was also found that a positive and significant relation exists between spelling skills of children whose first language is Arabic and second language English.

As for cross-linguistic syntactic awareness, it was found in a study investigating orthographic and cognitive factors in two languages, that a strong correlation exists between the syntactic awareness in Hebrew as the L1 and that in English as the L2 (Geva \& Siegel, 2000). It was argued that proficiency in syntactic awareness demands of the reader metalinguistic insight allowing the subject to discern the internal grammatical structure of sentences (Durgunoğlu, 2002). Similar findings were found in another study, where syntactical awareness in Spanish as the L1 among students in the 4th grade, was highly correlated with syntactical awareness in English as the L2 (Durgunoğlu, Mir, \& Ariño-Martí, 2002).

In relation to cross-linguistic transfer of morphological awareness, very few studies have dealt with the subject, resulting in scant knowledge in this area. In one of the few studies (Wang, Cheng, \& Chen, 2006), the contribution of morphological awareness towards reading Chinese as the L1 and English as the L2, was evaluated. It was found that morphological awareness of compound structures in English contributed to variance in both character reading and reading comprehension in Chinese. The authors concluded that children are able to apply morphological knowledge from one language to reading in another language that shares a similar morphological structure.

Regarding the development of literacy skills, it is claimed that even when a similarity exists in the process of acquiring those skills in alphabetical languages, there are still inter-linguistic differences that create variance in the process of reading development between languages. Based on the Psycholinguistic Grain Size Theory (Ziegler \& Goswami, 2005), there are languages in which the beginning reader has to face a problem of inconsistency, where a given language has several forms of pronunciations for the same orthographic units and some phonological units have a number of spelling forms. The assumption is that both types of inconsistency slow reading development. Since the extent of the inconsistency varies from lan- 
guage to language, there will be differences in reading development between languages.

According to the theory, reading acquisition will be easier and more rapid in those orthographies where a direct relation exists between graphemes and phonemes ("shallow orthographies"). In this case, readers rely mainly on strategies of decoding graphemes into phonemes. This means that children learning to read a language where the orthography is less consistent ("deep orthography") will have greater difficulties.

The authors of the Psycholinguistic Grain Size Theory emphasized that the different orthographies influence reading development among dyslectic readers as well (Ziegler \& Goswami, 2005). By this theory, although a phonologic deficit characterizes dyslexia in all languages, the deficit is expected to be more widespread among dyslectic individuals who are learning to read and write in a language that its orthography is considered deep. The authors claimed that despite the phonological deficit, there are still dyslectic readers who manage to achieve accurate decoding of the grapheme-phoneme relationship - in those alphabetical orthographies that are considered shallow. This is because very little ambiguity exists in decoding such orthographies. Such a claim points out that the major difficulty of children with dyslexia is in the phonological processing of small grain size words and sections (corresponding to graphemes and phonemes) with no regard to the orthography being learned.

Our present study is based on the assumption that an interdependent linguistic transfer from the L1 to the L2 will take place also from the L2 (English) to the L1 (Hebrew). Specifically, an improvement of linguistic and metalinguistic skills in a second language will bring about better performance in the same skills of the first language, following an intensive and systematic instruction program that focuses on the child's didactic needs. Such an improvement in a first language will be called Cognitive Retroactive Transfer-CRT.

\section{Method}

\section{Participants}

In this study, 20 Israeli 6th grade students who speak Hebrew as their first language were the participants. They all came from a middle socio-economic level, studying in an ordinary elementary school. These students were defined by their homeroom teacher as "weak learners" in both Hebrew and English, with an average grade below 70 . They had all been exposed to English classes since the $3 \mathrm{rd}$ grade. The students were picked at random from three different schools in Haifa, Israel. The sample included 9 boys and 11 girls with a combined average of 11.6 years of age.

After receiving written consent from their parents, the students were tested for fluency and reading comprehension in both languages. The students that received lower than a $70 \%$ grade in reading comprehension in both languages, lower than 100 correct words per minute in reading fluency in Hebrew, and lower than 50 correct words per minute in reading fluency in English, were classified as poor readers.

\section{Materials}

There were a total of 22 tests - 11 in each language:

Phonology Awareness Tests in English and Hebrew. Phonology awareness was tested by two types of assignments: analysis task and synthesis task. In the analysis task each participant was presented with 8 spoken words, which he had to segment into their phonemes. Examples are: bed $(=b-e-d)$, funny (=f-u-nn-y). In the synthesis task each participant was presented with 8 sequences of phonemes, and in each sequence he had to combine the phonemes to form a complete word. Examples are: 1-e-g (=leg), t-ea-ch-e-r (=teacher). The English versions were developed by Kahn-Horwitz (2006). The Hebrew versions were developed by Shany, Lachman, Shalem, Bahat, $\&$ Zeiger (2005). The percentage of correct responses out of the total was calculated.

Phonological Processing Test in English and Hebrew. Phonological processing was examined by the ability of the participants to read nonwords. In the English version each participant was requested to read aloud 20 meaningless words (KahnHorwitz, 2006). In the Hebrew version each participant was requested to read aloud 33 meaningless vowelized words (Shany et al., 2005). Examples of the words used include: ves, lun, grack, and shriff. The percentage of correct responses out of the total was calculated.

Word Identification Test in English and Hebrew. Each participant was requested to read aloud 46 words in the English version (Kahn-Horwitz, 2006) and 38 words in the Hebrew version (Shany et al., 2005), which were listed in an increasing order of difficulty. Examples are: stop, cat, chicken, number, soap and jumped. The percentage of correct responses out of the total was calculated.

Orthographic Knowledge Test in English and Hebrew. Participants were presented with 20 homophonic pairs of words (in each pair two words sound identical but are written differently), and in each pair they had to mark the one word that was spelled correctly. The English version was developed by Kahn-Horwitz (2006). The Hebrew version was developed by Shany et al. (2005). The percentage of correct responses out of the total was calculated.

Morphological Awareness Tests in English and Hebrew. Morphological awareness was tested by two types of assignments: One was a recognition test in which the participants were presented with 10 sentences in the English version and 9 sentences in the Hebrew version. The participants were asked to fill in the missing word in the sentence from a list of words underneath each sentence. All the words that were referred to the same sentence are inflections of the same infinitive/root. Examples are: I ing, watched); Tal television last night (watch, am watch-The other test was a production task in which the participants were presented as well with 10 sentences in the English version and 9 sentences in the Hebrew version. In this task each participant was requested to fill in a missing word in a sentence using a word, the root/infinitive of which was presented. Examples are: ___ (do) you go to the concert last week? Tomer (read) a book every night. The English versions were developed by Kahn-Horwitz (2006). The Hebrew versions were developed by Shany et al. (2005). The percentage of correct responses out of the total was calculated.

Syntactic Awareness Test in English and Hebrew. Syntactic awareness in English and in Hebrew was examined differently. In the English version the participants were presented with 12 sentences in which the correct order of the words was mixed up, and the participants had to reorganize the words in the right order (Kahn-Horwitz, 2006). The sentences were listed in an increasing order of difficulty. Examples are: are-home-We 
(=We are home); a-dog-have-You (=You have a dog). In the Hebrew version the participants were presented with a short text that contains compound sentences, in which an identification of a subject had to be made from a pronoun in the sentence (Shany et al., 2005). For example: "A lonely sailor found a lonely little boy in the street and adopted him". The question to be answered is "what does the word him refer to?" The percentage of correct responses out of the total was calculated.

Spelling Test in English and Hebrew. This skill was tested through dictation. In the English version the participants had to write down 3 sentences ( 20 words in total) dictated to them (Kahn-Horwitz, 2006). For example: "The dolphin swims in the deep water". In the Hebrew version the participants were requested to write down a short text (55 words in total) also dictated to them (Shany et al., 2005). The percentage of correct responses out of the total was calculated.

Reading Comprehension Test in English and Hebrew. In the English version the participants were requested to read a text nonverbally and then answer 10 multiple choice questions. The text was taken from a textbook (Vasan, 2000) and the questions were composed by the authors for this study. In the Hebrew version the participants were requested also to read a text nonverbally and then answer 5 open ended questions pertaining to reading comprehension (Tov-Li, 2000). The percentage of correct responses out of the total was calculated.

Reading Fluency in English and Hebrew. The participants were given a text to be read aloud. The English version contained 51 words (Kahn-Horwitz, 2006). The Hebrew text contained 308 words (Shany et al., 2005). Accuracy and speed were graded by calculating the number of words that were read correctly during one minute of reading.

\section{Procedure}

At the start, a battery of tests was given to the participants in order to test their linguistic and metalinguistic skills in both Hebrew and English. To reduce the interference on the results from tiredness of the participants, the order of the tests administered was rotated. The results of the tests in this phase were used for establishing a base line for comparison with the results obtained at the end of the intervention program. The tests were administered individually by one of the authors at the participants' home in a quiet room. All instructions were given in Hebrew, L1. The tests were administered in two sessions of approximately 60 minutes each - in each session all the tests were given in one of the two languages.

Upon completion of the tests and the analysis of the results, an intervention program was designed taking into account the weak and strong competencies of the participants. Since all of the participants exhibited a low level in all skills of English, it was decided to work with the participants on four major aspects, so that all the skills tested were covered in the intervention program. The linguistic aspects are as follows:

1) Decoding - Recognition of letters and their sounds; recognition of the sound of vowels and common combinations of letters, such as: th, ph, oo, ea, ch. Also, learning the pronunciation of common English forms of words, such as: bake-gamemade-snake; time-fine-like-bite, etc. and finally learning frequent word endings (for example: tion, sion). All of that was practiced by reading isolated words. In addition, approximately twice a month, an oral practice session was conducted in which a participant was asked to segment a spoken word into pho- nemes, as well as synthesize phonemes into complete words. This practice was done in order to increase phonological awareness.

2) Vocabulary-Expanding vocabulary was done by flashing frequently-used words, where the participants had to learn their meaning. As a practice of the vocabulary, the participants had to compose sentences using the words learned. They also had to translate into English short phrases. In every new session, a repetition of the previously-taught words was made before new words were introduced. All the words learned were given also printed in a list, so the participants could study them at home. Approximately every two weeks, a dictation was conducted on words taken from that list.

3) Grammar-A gradual and systematic instruction of the following grammar subjects was undertaken: the use of "a/an"; the auxiliary verb "to be"; have/has; present simple; present progressive; past simple. The learning of the tenses included declarative sentences, interrogative sentences and negative, using supporting cards which specify the appropriate grammatical rules. The participants practiced all the grammar rules by completing work sheets in class and later at home. The syntax aspect was also learned by an instruction of the syntactical rules regarding the correct order of words in an English sentence. The practice included mixing up the correct order of words in a sentence and requiring participants to reorganize it correctly.

4) Reading-The participants practiced fluent reading of texts with emphasis on speed and accuracy. Exercising reading speed was performed by repeated reading of the same text/ paragraph. In the following session, a practice of reading comprehension skills of the same text took place. The comprehendsion skills and strategies that were practiced were: making predictions and activating prior knowledge, figuring out unknown words, locating information in the text, story retelling and finally giving a title to each paragraph.

In summary, the intervention program was composed of a series of lessons in which English linguistic skills were studied. Both the supporting cards and the work sheets were prepared by the authors themselves. Every session was carried out by a teacher and two students in a quiet and isolated room. From the beginning, the students participating in the program were divided equally and randomly into two groups with 10 members in each group. The lessons for one of the two groups were given by one of the authors who is a qualified remedial teacher. The second group was taught by an English teacher with training in teaching children with learning disabilities. This teacher was subjected to continuous instructions by the authors throughout the program as to the contents of the lessons and as to the appropriate form of instruction. This was to ensure that the lessons given to the two groups were of equal form. The program was spread over five months with classes of 45 minutes each, taking place twice weekly.

At the end of the intervention program, all participants were given the same test batteries in English that were given before the intervention program. This was done in order to test for possible improvement in English linguistic skills, as a result of the intervention program. Afterwards, the test batteries were given also in Hebrew, in order to test for possible improvement in the same linguistic skills in L1. Summing up the results will provide possible evidence for the cognitive retroactive transfer hypothesis (CRT). 


\section{Results}

In order to test the validity of the study theme (according to which an intervention program for improving linguistic skills in English as a second language will result in an improvement of equivalent skills in Hebrew as the first language), a nonparametric test (Wilcoxon test) for dependent samples was conducted in order to examine the statistical significance of the differences in English linguistic skills before and after the intervention program. Likewise, a similar test will be conducted later to examine the statistical significance of the differences in linguistic skills in Hebrew before and after the intervention program. In cases where a participant had reached an optimal result in a given test before the intervention program, the grade was not entered into the statistics calculations. The mean scores are presented in percentages in Table 1, as well as their standard deviations for each linguistic skill and the $\mathrm{z}$ values before and after the intervention program.

The results presented in Table 1 show a statistically significant difference between the means of all linguistic skills in English before and after the intervention program. It appears from the data that as a result of the intervention program, the participants have significantly improved in all their linguistic skills in English. In order to test the validity of the study theme, an additional examination must be conducted also for a possible significant improvement in linguistic skills in Hebrew brought about by the intervention program. Also for this purpose a nonparametric test (Wilcoxon test) for dependent samples was conducted.

In Table 2, mean scores are presented in percentages as well as their standard deviations for each linguistic skill and the $\mathrm{z}$ values obtained in Hebrew before and after the intervention program.

The results presented in Table 2, point to a statistically sig-

Table 1.

Means, standard deviations and $\mathrm{z}$ values of the scores on the linguistic tasks in English before and after the intervention program.

\begin{tabular}{|c|c|c|c|c|c|c|}
\hline & \multicolumn{3}{|c|}{ Before } & \multicolumn{2}{|c|}{ After } & \multirow[b]{2}{*}{ Z } \\
\hline & $\mathrm{N}$ & M & $\mathrm{SD}$ & M & SD & \\
\hline $\begin{array}{l}\text { Phonological } \\
\text { awareness-analysis task } \\
\text { in English }\end{array}$ & 18 & 53.72 & 25.05 & 90.39 & 10.95 & $-3.64^{*}$ \\
\hline $\begin{array}{l}\text { Phonological } \\
\text { awareness-synthesis task } \\
\text { in English }\end{array}$ & 18 & 71.17 & 18.69 & 95.22 & 8.65 & $-3.76^{*}$ \\
\hline Reading fluency in English & 20 & 15.60 & 9.90 & 48.45 & 16.14 & $-3.92^{*}$ \\
\hline $\begin{array}{c}\text { Reading comprehension in } \\
\text { English }\end{array}$ & 20 & 25.00 & 15.73 & 59.50 & 13.17 & $-3.98^{*}$ \\
\hline Word identification in English & 20 & 48.70 & 13.99 & 82.20 & 7.14 & $-3.92^{*}$ \\
\hline Nonword reading in English & 20 & 22.75 & 14.28 & 79.00 & 15.01 & $-3.93^{*}$ \\
\hline $\begin{array}{c}\text { Orthographic knowledge in } \\
\text { English }\end{array}$ & 20 & 62.75 & 13.13 & 85.50 & 8.41 & $-3.94^{*}$ \\
\hline Spelling in English & 20 & 30.75 & 11.04 & 83.50 & 8.60 & $-3.93^{*}$ \\
\hline $\begin{array}{l}\text { Morphological } \\
\text { awareness-recognition } \\
\text { task in English }\end{array}$ & 20 & 25.00 & 17.01 & 77.00 & 12.18 & $-3.94^{*}$ \\
\hline $\begin{array}{l}\text { Morphological } \\
\text { awareness-production } \\
\text { task in English }\end{array}$ & 20 & 9.00 & 9.68 & 60.00 & 14.51 & $-3.96^{*}$ \\
\hline Syntactic awareness in English & 20 & 20.25 & 12.40 & 55.15 & 14.49 & $-3.93^{*}$ \\
\hline
\end{tabular}

Note: ${ }^{*} p<.001$.

Table 2.

Means, standard deviations and $\mathrm{z}$ values of the scores on the linguistic tasks in Hebrew before and after the intervention program.

\begin{tabular}{|c|c|c|c|c|c|c|}
\hline & \multicolumn{3}{|c|}{ Before } & \multicolumn{2}{|c|}{ After } & \multirow[b]{2}{*}{$\mathrm{Z}$} \\
\hline & $\mathrm{N}$ & M & SD & M & SD & \\
\hline $\begin{array}{c}\text { Phonological } \\
\text { awareness-analysis task } \\
\text { in Hebrew }\end{array}$ & 19 & 44.95 & 24.51 & 87.68 & 11.73 & $-3.84^{* * *}$ \\
\hline $\begin{array}{c}\text { Phonological } \\
\text { awareness-synthesis task } \\
\text { in Hebrew }\end{array}$ & 17 & 73.76 & 13.92 & 97.88 & 4.72 & $-3.62^{* * *}$ \\
\hline Reading fluency in Hebrew & 20 & 78.65 & 21.21 & 90.25 & 19.92 & $-3.89^{* * *}$ \\
\hline $\begin{array}{c}\text { Reading comprehension in } \\
\text { Hebrew }\end{array}$ & 20 & 36.25 & 11.68 & 50.50 & 11.91 & $-3.55^{* * *}$ \\
\hline Word identification in Hebrew & 20 & 79.95 & 7.46 & 89.10 & 6.44 & $-3.89^{* * *}$ \\
\hline Nonword reading in Hebrew & 20 & 38.20 & 18.18 & 56.80 & 23.06 & $-3.83^{* * *}$ \\
\hline $\begin{array}{c}\text { Orthographic knowledge in } \\
\text { Hebrew }\end{array}$ & 10 & 82.00 & 16.87 & 86.00 & 14.68 & -1.90 \\
\hline Spelling in Hebrew & 20 & 77.70 & 13.81 & 82.85 & 12.19 & $-3.70^{* * *}$ \\
\hline $\begin{array}{l}\text { Morphological } \\
\text { awareness-recognition } \\
\text { task in Hebrew }\end{array}$ & 12 & 84.42 & 7.35 & 94.50 & 8.77 & $-2.50^{*}$ \\
\hline $\begin{array}{l}\text { Morphological } \\
\text { awareness-production } \\
\text { task in Hebrew }\end{array}$ & 20 & 76.90 & 7.90 & 86.80 & 8.45 & $-2.92^{* *}$ \\
\hline Syntactic awareness in Hebrew & 20 & 72.30 & 9.49 & 81.50 & 6.60 & $-3.42^{* *}$ \\
\hline
\end{tabular}

Note: ${ }^{*} p<.05,{ }^{* *} p<.01,{ }^{* * *} p<.001$.

nificant difference in most means of the linguistic skills in Hebrew before and after the intervention program. The only test in which no statistically significant improvement was made was in the orthographic knowledge in Hebrew $(Z=-1.90 ; p>.05)$. These findings indicate that as a result of the intervention program in English, significant improvements were obtained in all linguistic skills in Hebrew with the exception of the Hebrew orthography.

In addition to examining the study theme, a possible correlation was searched between the levels of proficiency in English linguistic skills and those of Hebrew after the intervention program. A Spirman correlation test was used for this purpose. As for an index for phonological awareness, a positive and significant correlation was found in the analysis task $\left(\mathrm{r}_{\mathrm{s}}=.66, p<.01\right)$, as well as in the synthesis task $\left(\mathrm{r}_{\mathrm{s}}=.70, p<.01\right)$. That is, as the phonological awareness of the subject was higher in L2 (English), so was it higher in L1 (Hebrew). Another significant positive correlation was found between the spelling skills of the subjects in English and in Hebrew $\left(\mathrm{r}_{\mathrm{s}}=.48, p<.05\right)$.

On the other hand, in all other linguistic skills tested, the correlations were low, however significat: reading fluency $\left(\mathrm{r}_{\mathrm{s}}=.23\right.$, $p>.05)$, reading comprehension $\left(\mathrm{r}_{\mathrm{s}}=.28, p>.05\right)$, word identification $\left(\mathrm{r}_{\mathrm{s}}=.13, p>.05\right)$, nonword reading $\left(\mathrm{r}_{\mathrm{s}}=.33, p>.05\right)$, morphological awareness-recognition task $\left(\mathrm{r}_{\mathrm{s}}=.24, p>.05\right)$, morphological awareness-production task $\left(\mathrm{r}_{\mathrm{s}}=.21, p>.05\right)$, and syntactic awareness $\left(\mathrm{r}_{\mathrm{s}}=.26, p>.05\right)$.

In summary, it appears from these findings that as a result of the intervention program, which improved the English linguistic skills, a parallel improvement was achieved in all Hebrew linguistic skills, with the exception of orthographic knowledge. When a possible correlation was searched between linguistic 
skills in English and those in Hebrew after the intervention program, the only significant correlation was found in phonological awareness (both analysis and synthesis tasks) as well as in spelling skills.

\section{Discussion}

The present study intended to further develop the Cummin's (1991) theory which states that L1 linguistic and metalinguistic skills are transferable to the L2. The present study explored whether linguistic and metalinguistic skills are transferable in an opposite direction, from the L2 to the L1, namely if there is CRT of skills.

The findings of the present study indicate that the English intervention program improved students' achievement on all English tests, which motivated us to test if there was a similar progress on the Hebrew linguistic and met linguistic skills, although they were not subjected to a similar Hebrew intervention program.

The results of the Hebrew tests indicated clearly that there was significant progress on the phonological domain on all tests, such results indicate clearly the occurrence of a CRT of skills, namely that English phonological abilities were transferred to Hebrew the L1 of the students Note, that the classic findings of transfer of skills are discussing their findings taking the orientation of straight forward relationship from L1 to L2 without consideration of the transfer in an opposite direction fro L2 to L1 (cf. Abu-Rabia \& Siegel, 2002; Gholamain \& Geva, 1999; Muter \& Diethelm, 2002; Quiroda, Lemsmostafapor, Abbott, \& Berninger, 2002; Sparts, Pratton, Ganschow, Humbach, \& Jeworsky, 2008).

These results suggest that linguistic transfer operation is a modular process, namely phonological experiences with speech sounds in the L2 lead to higher metacognitive abilities in the L2 and positively influence similar met cognitive abilities in other languages. According to Koda (2007) the segmentation of words into their speech sounds is not language-specific; experiences in one language may reflect on other languages of the learner.

Additionally, Hebrew reading accuracy of isolated words was improved which indicates the transfer of this skill from L2 to L1. Note, that this has occurred in Hebrew the L1 of the learners where they did not receive any direct linguistic intervention (Durgunoglo, Nagy, \& Hancin-Bhatt, 1993; Geva, WadeWooly, \& Shany, 1997; Meschyan \& Hernandez, 2002). Such results enhance the notion that the met linguistic maturity process functions as a modular process that influences similar linguistic skills in other languages. It has been stated that word recognition skills are strongly influenced by other orthographic, phonological, and morphological skills, namely when these skills are improved then word recognition improves accordingly (Schiff \& Calif, 2007). Furthermore, the same pattern was noticed in the fluency of reading Hebrew texts, the improvement in fluency and accuracy of Hebrew which indicates again the transfer of this skill through a modular process (cf. Dominguer De Ramirez \& Shapiro, 2007).

Consistently, the English reading comprehension results were improved after the intervention program, such a result seem to positively influence the same skill in Hebrew, the L1 of the students, which showed a similar pattern (cf. Sparks et al., 2008; Durgunoglu, 2002; Van Gelderen et al., 2004). According to Durgunoglu (2002) reading strategies significantly in- fluence reading comprehension, and since reading strategies are considered cognitive domain, they are expected to be transferable from one language to another, regardless of language order, L1 or L2.

Furthermore, the syntactic ability of the students was improved not only in English as a result of the intervention program, but also in Hebrew the L1 of the students (cf. Da Fantura \& Siegel, 1995; Durgunoglu, Mir, \& Arino-Martl, 2002; Geva \& Siegel, 2002). According to Durgunoglu (2002), mastering syntactic skills requires high sensitivity to inner grammatical structures of sentences, and since such a skill considered a met cognitive ability, it's more likely to be transferable from one language to another regardless of direction, from L1 to L2 and vice versa. Further, similar results were obtained in English morphology and Hebrew morphology which reveals that morphological awareness was transferred from English to Hebrew (cf. Schiff \& Calif, 2007; Wang, Cheng, \& Chin, 2006).

Consistently, the spelling results indicate similar improvement patterns in English as well as in Hebrew. Such results mean that English spelling abilities were transferred to Hebrew, the L2 of the students. Namely, direct spelling experiences in one language may influence similar abilities in other languages of the same learner (cf. Abu-Rabia \& Siegel, 2002; Sparks et al., 2008). According to Durgunoglo (2002) strong spelling skills requires sensitivity of readers to the high frequent patterns of orthography and phonology of the specific language, which ultimately reflected positively on the same skill in the other language.

However, the orthographic results revealed a different pattern; the English orthographic results were improved as a result of the intervention program, while this improvement was not reflected on the Hebrew orthographic skills. This is to say that the Hebrew orthographic skills were not improved because the English orthographic experiences were not transferred to Hebrew the L1 of the students. This result seems to be consistent with previous studies that failed to find orthographic cross language transfer (Wang, Park, \& Lee, 2006; Wang, Perfetti, \& Liu, 2005).

According to Abu-Rabia and Siegel (2002) orthographic skills are language specific and different languages are characterized by different and unique orthographic writing rules. Thus, in order to improve certain orthographic language awareness, learners should be exposed directly to that specific writing system. This is, because orthographic knowledge is language specific, and in order to develop such knowledge readers need direct instruction and extensive exposure to the specific complex orthographic rules of the specific writing system. Such operations may not be transferable to other languages because orthography is a concrete code, while phonology, for instance, is an abstract code that makes it's modular met cognitive transferability from one language to another, easier and faster regardless of direction, from L1 to L2 and vice versa (Abu-Rabia \& Sanitsky, 2010).

Overall, the Hebrew results indicated significant improvement, except for the orthographic results. These findings confirm the existence of a Cognitive Retroactive Transfer of phonological awareness, phonological processing, word recognition, fluency, reading comprehension, syntactic awareness, morphological awareness and spelling skills from the English, the L2 of the students to Hebrew, the L1 of the students. This is to say that transfer of met cognitive abilities may also occur retroactively through a modular process, not only from L1 to L2, but 
also from L2 to L1. It's important to note that our 6th graders were poor readers, which highlights the importance and relevance of the present findings across language acquisition levels. In other words, transfer of skills does not occur only among regular or/and good readers but also among poor readers during their early stages of language acquisition, provided that curricula designers keep teaching direct, systematic, and well constructed.

\section{Limitations of the Study}

The present study suffers from a few limitations that should be taken into consideration when interpreting its' results. The small sample that threatens the ability of generalization; the English tests were taken from a non-standardized English battery for students of English as a second language; and that the post tests were administered only once, which raises the issue of future behavior of this improvement: Will it last for a long time, or disappear after a certain period of time?

\section{REFERENCES}

Abu-Rabia, S., \& Sanitzky, I. (2010). Advantages of bilingualism over monolingualism in learning a third language. Bilingual Research Journal, 32, 173-199.

Abu-Rabia, S., \& Siegel, L. S. (2002). Reading, syntactic and working memory skills of bilingual Arabic-speaking children. Journal of Psycholinguistic Research, 31, 661-678. doi:10.1023/A:1021221206119

Abu-Rabia, S., \& Siegel, L. S. (2003). Reading skills in three orthographies: The case of trilingual Arabic-Hebrew-English speaking Arab children. Reading and Writing: An Interdisciplinary Journal, 16, 611634. doi:10.1023/A:1025838029204

Cisero, C. A., \& Royer, J. M. (1995). The development and cross-language transfer of phonological awareness. New York: Longman.

Cummins, J. (1991). Interdependence of first and second language proficiency in bilingual children. In E. Bialystock (Ed.), Language processing in bilingual children (pp. 70-89). Cambridge: Cambridge University Press. doi:10.1017/CBO9780511620652.006

Domínguez De Ramírez, R., \& Shapiro, E. S. (2007). Cross-language relationship between Spanish and English oral reading fluency among Spanish-speakers English language learners in bilingual education classrooms. Psychology in the School, 44, 795-806. doi:10.1002/pits.20266

Durgunoğlu, A. Y. (2002). Cross-linguistic transfer in literacy development and implications for language learners. Annals of Dyslexia, 52, 189-204. doi:10.1007/s11881-002-0012-y

Durgunoğlu, A. Y., Mir, M., \& Ariño-Martí, S. (2002). The relationship between bilingual children's reading and writing in their two languages. In S. Ransdell, \& M. L. Barbier (Eds.), Psycholinguistic approaches to understanding second-language writing (pp. 81-100). Dordrecht: Kluwer.

Eviatar, Z., \& Ibrahim, R. (2004). Morphological and orthographic effects on hemispheric processing of nonwords: A cross-linguistic comparison. Reading and Writing: An Interdisciplinary Journal, 17, 691-705. doi:10.1007/s11145-004-2659-8

Geva, E. (1995). Orthographic and cognitive processing in learning to read English and Hebrew. In I. Taylor, \& R. D. Olson (Eds.), Scripts and literacy (pp. 277-291). Dordrecht: Kluwer. doi:10.1007/978-94-011-1162-1_18

Geva, E., \& Siegel, L. (2000). Orthographic and cognitive factors in the concurrent development of basic reading skills in two languages. Reading and Writing: An Interdisciplinary Journal, 12, 1-30. doi:10.1023/A:1008017710115

Geva, E., Wade-Wooley, L., \& Shany, M. (1997). The development of reading efficiency in first and second language. Scientific Studies of Reading, 1, 119-144. doi:10.1207/s1532799xssr0102_2
Geva, E., Yaghoub-Zadeh, Z., \& Schuster, B. (2000). Understanding individual differences in word recognition skills of ESL children. Dyslexia, 50, 123-154.

Gholamain, M., \& Geva, E. (1999). Orthographic and cognitive factors in the concurrent development of basic reading skills in English and Persian. Language Learning, 49, 183-217. doi:10.1111/0023-8333.00087

Goodman, K. S. (1971). Psycholinguistic universals in the reading process. In P. Pimsleur \& T. Quinn (Eds.), The psychology of second language learning (pp. 135-142). Cambridge: Cambridge University Press.

Kahn-Horwitz, J. (2006). English as a foreign language-A non formal test battery. Haifa: Yozma.

Koda, K. (1999). Development of L2 intraword orthographic sensitivity and decoding skills. Modern Language Journal, 83, 51-64. doi:10.1111/0026-7902.00005

Koda, K. (2007). Reading and language learning: Cross linguistic constraints on second language reading development. Language Learning, 57, 1-44. doi:10.1111/0023-8333.101997010-i1

Lee, J. W., \& Schallert, D. L. (1997). The relative contribution of L2 language proficiency and L1 reading ability to L2 reading performance: A test of the threshold hypothesis in an EFL context. Tesol Quarterly, 31, 719-739. doi:10.2307/3587757

Leikin, M., Share, D. L., \& Schwartz, M. (2005). Difficulties in L2 Hebrew reading among Russian-speaking second graders. Reading and Writing, 18, 455-472. doi:10.1007/s11145-005-8919-4

Miller-Guron, L., \& Lundberg, I. (2000). Dyslexia and second language reading: A second bite at the apple? Reading and Writing: An Interdisciplinary Journal, 12, 41-61. doi:10.1023/A:1008009703641

Muter, V., \& Diethelm, K. (2001). The contribution of phonological skills and letter knowledge to early reading development in a multilingual population. Language Learning, 51, 187-219. doi:10.1111/1467-9922.00153

Quiroda, T., Lemos-Britton, Z., Mostafapour, E., Abbott, R. D., \& Berninger, V. W. (2002). Phonological awareness and beginning reading in Spanish-speaking ESL first graders: Research into practice. Journal of School Psychology, 40, 85-111. doi:10.1016/S0022-4405(01)00095-4

Shany, M., Lachman, D., Shalem, Z., Bahat, A., \& Zeiger, T. (2005). "Alep-Taph"-An assessment system for reading and writing disabilities. Tel Aviv: Yesod Publishing.

Shimron, J., \& Sivan, T. (1994). Reading proficiency and orthography: Evidence from Hebrew and English. Language Learning, 44, 5-27.

Siegel, L., Share, D., \& Geva, E. (1995). Evidence for superior orthographic skills in dyslexics. Psychological Science, 6, 250-254. doi:10.1111/j.1467-9280.1995.tb00601.x

Sparks, R. (1995). Examining the linguistic coding differences hypothesis to explain individual differences in foreign language learning. Annals of Dyslexia, 45, 187-214. doi:10.1007/BF02648218

Sparks, R., Patton, J., Ganschow, L., Humbach, N., \& Javorsky, J. (2008). Early first-language reading and spelling skills predict later second-language reading and spelling skills. Journal of Educational Psychology, 100, 162-174. doi:10.1037/0022-0663.100.1.162

Sparks, R., Philips, L., \& Javorsky, J. (2003). College students classified as having learning disabilities and attention deficit hyperactivity disorder and the foreign language requirement. Foreign Language Annals, 36, 325-337. doi:10.1111/j.1944-9720.2003.tb02117.x

Tov-li, E. (2000). A reading and writing test battery for 1 st - 9th graders (in Hebrew). Kiriat Bialik: Ach.

Van Gelderen, A., Schoonen, R., De Glopper, K., Hulstijn, J., Simis, A., Snellings, P., \& Stevenson, M. (2004). Linguistic knowledge, processing speed, and metacognitive knowledge in first- and secondlanguage reading comprehension: A componential analysis. Journal of Educational Psychology, 96, 19-30. doi: $10.1037 / 0022-0663.96 .1 .19$

Vazan, N. (2000). More unseens 1. Ra'anana: Eric Cohen Books.

Verhoeven, L. (1994). Transfer in bilingual development: The linguistic interdependence hypothesis revisited. Language Learning, 44, 381415. doi:10.1111/j.1467-1770.1994.tb01112.x

Wang, M., Cheng, C., \& Chen, S. (2006). Contribution of morphological awareness to Chinese-English biliteracy acquisition. Journal of 


\section{S. ABU-RABIA, D. BLUESTEIN-DANON}

Educational Psychology, 98, 542-553.

doi:10.1037/0022-0663.98.3.542

Wang, M., Park, Y., \& Lee, K. R. (2006). Korean-English biliteracy acquisition: Cross-language phonological and orthographic transfer. Journal of Educational Psychology, 98, 148-158.

doi:10.1037/0022-0663.98.1.148

Wang, M., Perfetti, C. A., \& Liu, Y. (2005). Chinese-English biliteracy acquisition: Cross-language and writing system transfer. Cognition 97, 67-88. doi:10.1016/j.cognition.2004.10.001

Ziegler, J. C., \& Goswami, U. (2005). Reading acquisition, developmental dyslexia, and skilled reading across languages: A psycholinguistic grain size theory. Psychological Bulletin, 131, 3-29.

doi:10.1037/0033-2909.131.1.3 